\title{
THIS DOES NOT ADD UP
}

\section{STEPHEN ATTONG}

In response to Lu's spoken word "This is a Test," this photo essay is an attempt to visually express some of the themes that popped in my head when listening to Lu's work. There were feelings of isolation, helplessness, the idea of being just another cog in the machine, and the fact that it's a system that

\section{KEYWORDS}

schools, testing, standardized testing, photo essay does more to halt a child's learning than to facilitate it.
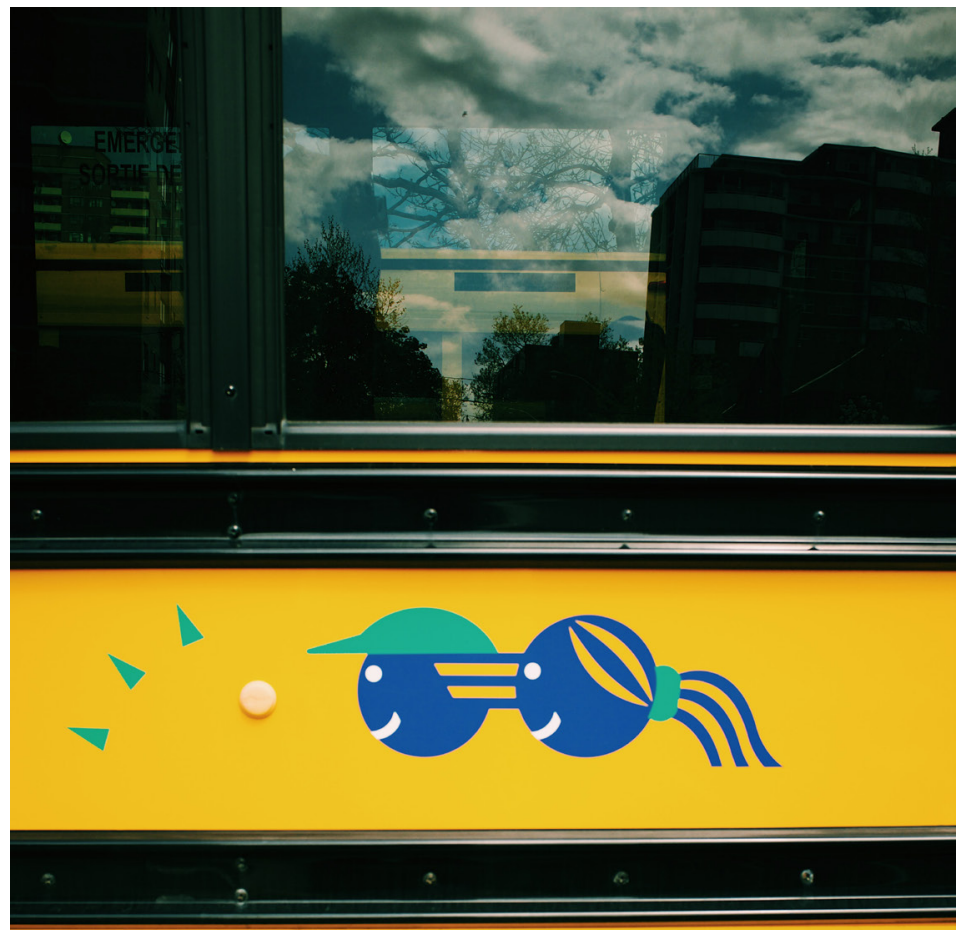

On the Journey of Learning

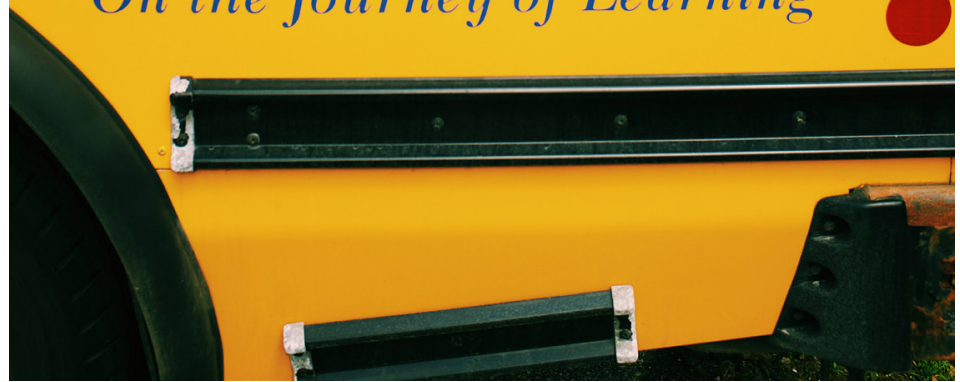



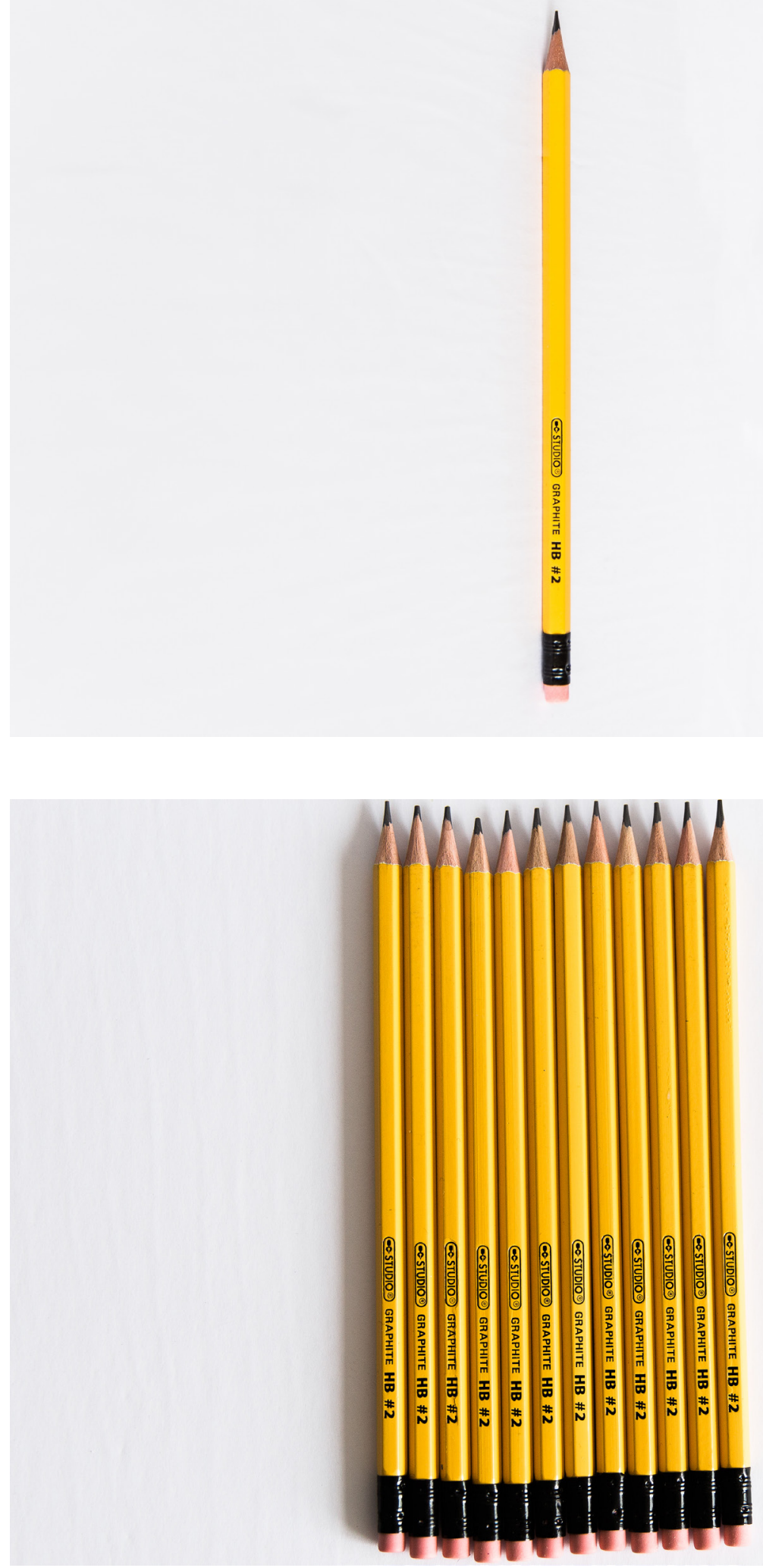
58 : This Does Not Add Up

\section{Corporate greed.}

Corp greed is protected by copyright, enemies will be prosecuted to the maximum extent possible.

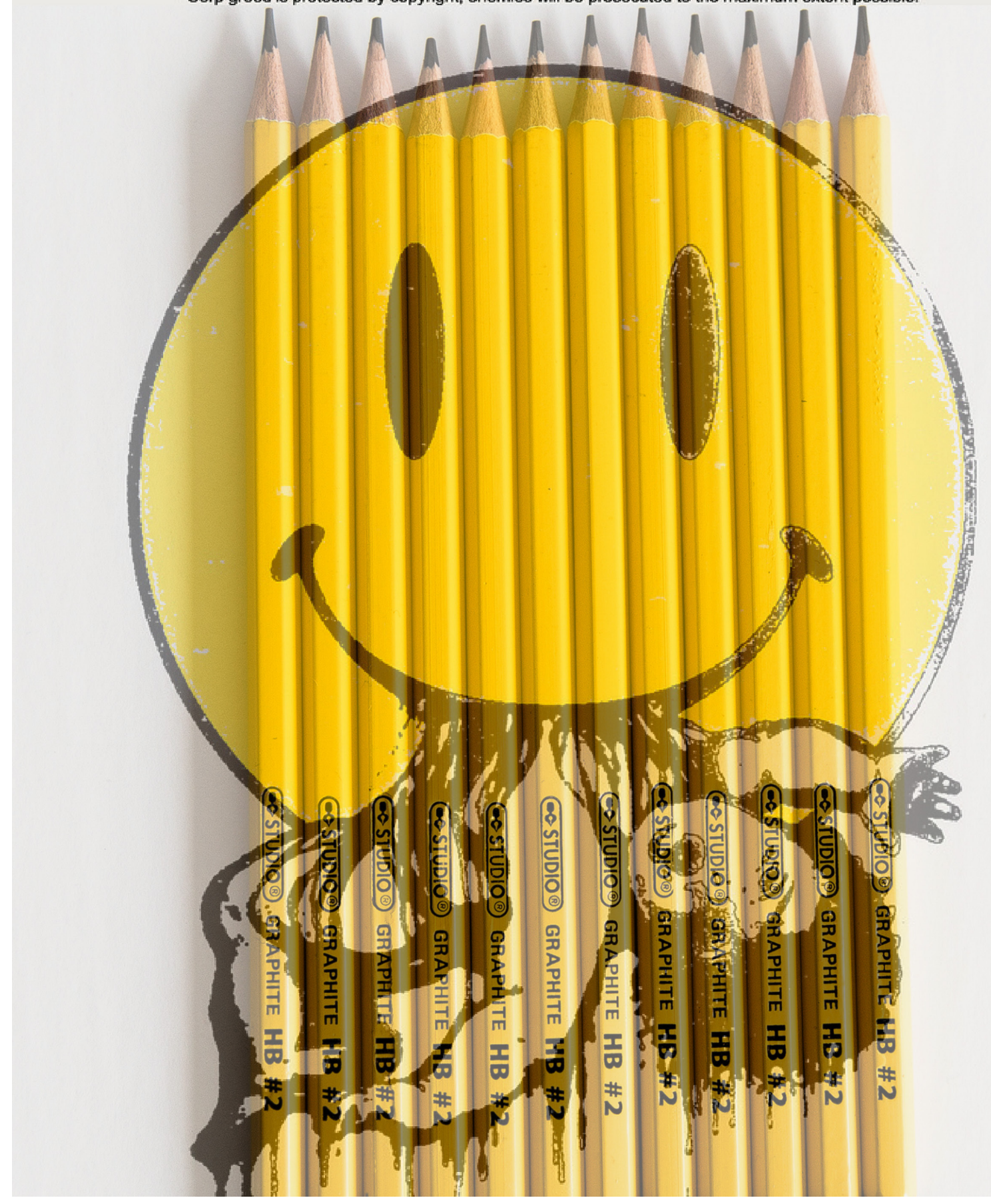


in:cite journal vol. $1: 59$
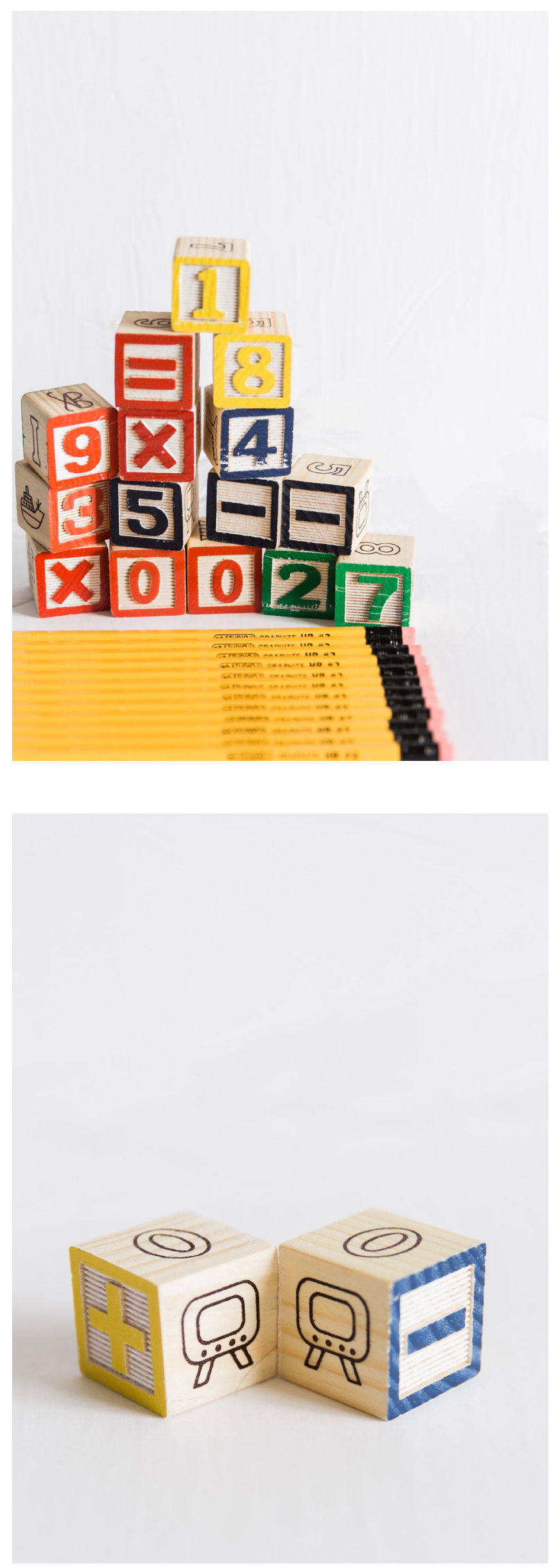
60 : This Does Not Add Up

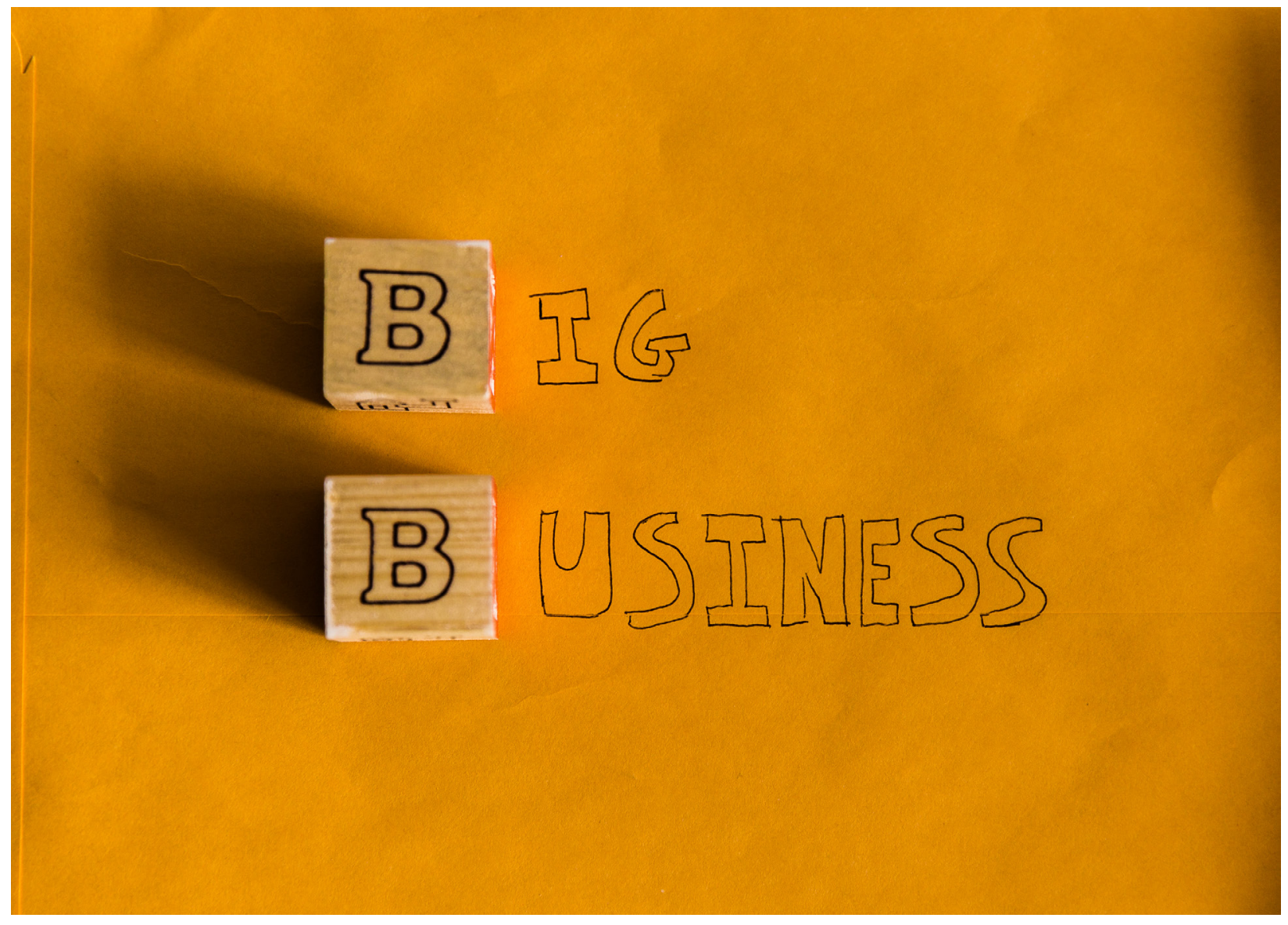


in:cite journal vol. $1: 61$

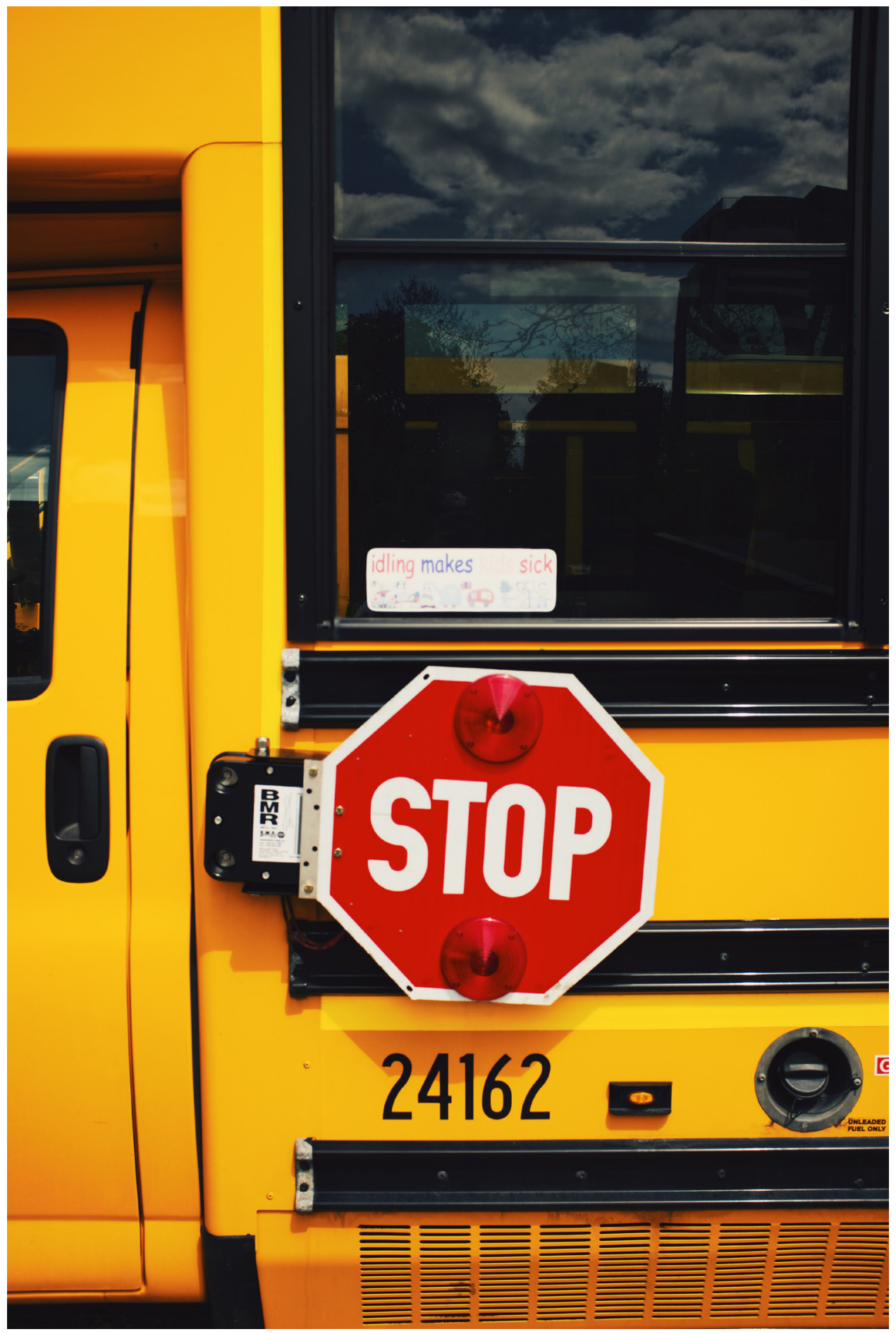

